\title{
Estigma em blogs de pessoas com deficiência auditiva ${ }^{1}$
}

\section{Sandra Portella Montardo e Bruna Chilanti Cordeiro}

\section{Resumo}

0 tema deste artigo é a identificação do estigma em blogs de pessoas com deficiência auditiva.0 fato de que nesta rede os deficientes auditivos são autores de blogs justifica a investigação do conceito de estigma (GOFFMAN,1988) e a verificação de sua incidência na rede considerada. Quanto à metodologia, a netnografia (HINE, 2005; KOZINETS, 2002) é utilizada para a identificação, seleção e obtenção de dados dos blogs escolhidos. Verificouse uma baixa ocorrência de estigma em postagens e em comentários. No entanto, na maioria das ocorrências, o contexto de seu aparecimento era proveniente de questões referentes a a alinhamento intragrupal de deficientes auditivos.

Palavras-chave

Estigma. Blogs. Pessoas com deficiência auditiva.

Sandra Portella Montardo | sandramontardo@feevale.br Doutora em Comunicação Social pela Pontifícia Universidade Católica do Rio Grande do Sul - PUCRS. Professora e Pesquisadora do Centro Universitário Feevale.

\section{Bruna Chilanti Cordeiro | brunacc@feevale.br}

Estudante de Graduação do Curso de Comunicação Social. Bolsista de Iniciação Científica do Centro Universitário Feevale.

\section{Introdução}

A inclusão social (IS) de pessoas com deficiência e de seus familiares em redes sociais na web, bem como a identificação de padrões de socialização estabelecidos nestas redes, é o objetivo do projeto Inclusão social via socialização on-line de Pessoas com Necessidades Especiais (PNE).

Em um artigo anterior (MONTARDO; PASSERINO, 2007), abordamos vários conceitos de inclusão social (IS) e estabelecemos sua relação com o conceito de inclusão digital (ID). Nele, interpretamos que a IS consiste na promoção de autonomia de indivíduos que se encontram, temporariamente ou não, e, sob algum aspecto específico, em desvantagem a outros grupos sociais (AZEVED0; BARROS, 2004; LADEIRA; AMARAL, 1999; SPOSATI, 2006). Neste contexto, compreende-se a IS como um processo permanente, embora não constante, em que todos podem estar simultaneamente incluídos em algumas situações e excluídos de outras. A ID pode ser vista como uma faceta da IS (WARSCHAUER, 2006), ao prover de autonomia os sujeitos que a utilizem para buscar 
as quatro utopias básicas: autonomia de renda, desenvolvimento humano, equidade e qualidade de vida (SPOSATI, 2006).

Visando identificar a IS de PNE e de seus familiares em blogs, mapeamos e analisamos uma rede temática sobre autismo e Síndrome de Asperger (SA) em blogs (MONTARDO; PASSERINO, 2008)². Uma segunda rede de pais de crianças foi identificada na web, dessa vez sobre a Síndrome de Down (SD) e organizada, principalmente, em fotologs (MONTARDO; GOEDTEL; ETCHEGARAY, 2008; MONTARD0, 2008). ${ }^{3}$ Um terceiro artigo dá conta da biossocialidade on-line de pessoas com deficiência auditiva e de informados também em blogs. (MONTARD0, 2009).

A partir deste último artigo, surgiu o interesse de investigar a ocorrência do estigma nesta rede. Antes de tudo, é importante que se levante as características da deficiência auditiva para que, então, as relacione com as habilidades exigidas para a socialização on-line em blogs.
Essa questão é fundamental para entender a incidência (ou não) do estigma nessas redes.

\section{Deficiência auditiva e estigma}

Segundo Redondo e Carvalho (2000, p. 5), a deficiência é um assunto desconhecido no Brasil, o que se reflete "na ausência de estatísticas brasileiras tanto a respeito de seu número real quanto das formas de assistência disponíveis, de sua integração social e de sua inclusão no mercado de trabalho". Quando aprovadas, as leis para pessoas com deficiência têm implantação lenta ou apresenta falhas na sua regulamentação.

Deficiência auditiva ou surdez $z^{4}$ ocorrem quando problemas em alguma das partes do ouvido (ouvido externo, ouvido interno ou ouvido médio) prejudicam a audição em algum grau (REDONDO; CARVALHO, 2000). A incidência de rubéola na mãe, durante a gravidez, doenças hereditárias, assim como a ingestão de remédios sem receita médica, por parte da criança, ou a ocorrência de meningite nesta são algumas das causas

Este artigo foi produzido em função do Projeto Inclusão social via socialização on-line de Pessoas com Necessidades Especiais (PNE), que conta com financiamento do Edital Universal do CNPq.

Neste estudo, identificamos três tipos de atuação dos usuários desta rede: os promotores de IS (autores de postagens e de comentários), aqueles que apenas dela usufruem (leitores de comentários), e os que fazem as duas coisas, sob forma de conteúdo informativo ou de apoio emocional. Esses blogs analisados funcionam, assim, como uma extensão de Associação de Pais quanto aos desafios postos pelo autismo e pela Síndrome de Asperger, questões que ainda não estão totalmente definidas no campo científico.

Nesta rede, cujo capital social é relacional e em que se observa confiança no ambiente social, talvez, pelo fato de que todos os fotologs analisados estão linkados a um agregador de fotologs sobre SD, as fotos aparecem como meio de revelar uma deficiência reconhecida imageticamente e de servir como instrumento de identificação de pessoas que se encontram presencialmente com frequência. Pode-se dizer que todos aqui promovem e usufruem a/da IS, inclusive, potencialmente, as próprias crianças com SD.

De acordo com Redondo e Carvalho (2000), deficiente auditivo é a auto-denominação favorita dos surdos adultos cuja perda auditiva é de leve a moderada. Já Moura (2000) opta por chamar os sujeitos com surdez de Surdo, com letra maiúscula. Neste artigo, usaremos os termos nos dois sentidos, indistintamente, com letra minúscula. 
conhecidas da deficiência auditiva, sendo que em $50 \%$ dos casos não se chega a identificá-las (REDONDO; CARVALHO, 2000).

Compreender o processo de aquisição da linguagem é necessário para que se investigue as possibilidades de pessoas com deficiência auditiva escreverem em blogs. Entre os métodos existentes para tanto, os principais são:

a) Oralismo: consiste em fazer a pessoa surda ${ }^{5}$ a ouvir e a falar, usando apenas a pista auditiva (MOURA, 2000; REDOND0; CARVALHO, 2000). Nesse método, o envolvimento da família no processo de aprendizagem é fundamental para 0 pleno desenvolvimento da criança. Se necessário, complementa-se a prática com método oral unissensorial (ênfase na audição com aparelhos auditivos, sem utilizar a leitura labial nem a língua de sinais) ou o método oral multissensorial (estimula todos os sentidos: audição - com aparelhos auditivos -, visão - leitura labial -, e tato, etc.; não utiliza a linguagem de sinais) (REDONDO; CARVALHO, 2000);

b) Língua de Sinais (LS): em função dos resultados insatisfatórios do método oralista, os estudos de Stokoe (1960), nos Estados Unidos, sobre a LS, "tanto no nível de sua estruturação interna como de sua gramática, provaram que ela tinha valor linguístico semelhante ao das línguas orais e que cumpria as mesmas funções, com possibilidades de expressão em qualquer nível de abstração" (apud MOURA, 2000, p. 56). Outra conclusão importante desses estudos é que a LS não prejudica habilidades orais prévias;

c) Comunicação Total (CT): mais que um método, a CT é considerada uma filosofia que consiste em utilizar todos os meios possíveis para a educação dos surdos: "oralização, prótese auditiva, gestos naturais, linguagem de sinais, expressão facial, alfabeto digital, leitura labial, leitura da escrita, [...]." (CORRÊA apud REDONDO; CARVALHO, 2000, p. 27);

d) Bilinguismo: congrega a LS e a oral (português), sem que uma interfira na outra. (REDONDO; CARVALHO, 2000).

Moura (2000) destaca que a LS continua a não ser reconhecida, sendo que apenas a escrita é considerada a verdadeira fonte de acesso à linguagem. No entanto, como a própria autora faz notar, onde houver surdos haverá a LS. Desde o século XIX, o surdo se sente discriminado, sem direito à sua própria língua. De acordo com Moura (2000), a educação baseada na LS colaboraria para que os surdos fossem vistos mais pela sua diferença do que pela sua deficiência, posicionando-se na sociedade não pela sua exclusão em relação a ela, mas por meio de uma identidade definida em sua positividade.

Na medida em que este estudo trata de relações sociais em blogs envolvendo pessoas com deficiência auditiva, vale considerar as questões 
levantadas por Goffman $(1988$, p. 7) sobre 0 estigma $^{6}$, que, em linhas gerais, é definido pelo autor como "a situação do indivíduo que está inabilitado para a aceitação social plena". 0 estigma requer uma relação social, consistindo em um rótulo depreciativo que uma pessoa ou grupo atribui a outra pessoa ou grupo, com a finalidade de deteriorar sua identidade. Pode-se dizer que esse movimento se funda na falta de credibilidade do estigmatizado frente ao não estigmatizado quanto a algum aspecto.

Para 0 autor, 0 estigma se revela na discrepância entre identidade social virtual (imputação de características a uma pessoa baseada em expectativas prévias) e a identidade social real (atributos que a pessoa realmente possui). $\mathrm{Ou}$ seja, por si só um traço característico não é bom nem mau, sendo que o estigma, configurado como fator depreciativo, existe a partir da relação entre atributo e estereótipo. Nas palavras de Goffman, "o normal e 0 estigmatizado não são pessoas, e sim perspectivas que são geradas em situações sociais durante os contatos mistos, em virtude de normas não cumpridas que provavelmente atuam sobre o encontro" (GOFFMAN, 1988, pp. 148-149).

Nesse sentido, é importante entender em que consiste uma comunidade de surdos ou a cultura surda. Segundo Mottez (1999), citada por Moura (2000), escolas residenciais, clubes, festas e competições esportivas que reúnam surdos são considerados lugares que podem servir de base para uma comunidade de surdos. Isso porque, em situações como essa, acredita-se que a pessoa com deficiência auditiva nunca vai ter a surdez como instrumento de discriminação contra si, estando em condições de posicionarse socialmente sem 0 esforço requerido na presença de ouvintes. Assim, estaria favorecida a estruturação positiva de sua identidade.

Já a cultura dos surdos, conforme Goggin e Newell (2003, p. 26), consiste em "pessoas que nascem ou se tornam surdas, usam linguagem de sinais como sua primeira língua, e identificam a si mesmos como sendo surdos enquanto também participam de atividades dentro da comunidade".

Quanto a essa questão, interpreta-se que Goffman (1988) faz uma leitura menos linear e mais complexa. Se em situações sociais mistas, em que as pessoas estigmatizadas e as ditas normais convivem, podem resultar em uma interação angustiada para ambas as partes, tal como pontuou Moura (2000), entre seus iguais há a possibilidade de os estigmatizados fazerem de sua "desvantagem" a base para organizar sua vida e, assim, concordarem com a resignação de viver de um modo incompleto.

Goffman observa uma certa ambivalência quanto aos modelos de identidade adquiridos pelo sujeito estigmatizado, já que este não consegue 
se conformar a eles. Com isso, cria-se uma situação em que um deficiente auditivo não se vê como surdo, nem o deficiente visual, como cego. É, portanto, na associação com os iguais, ou perante a separação deles, que haverá oscilações de identificação.

Quanto aos alinhamentos intragrupais dos estigmatizados, Goffman (1988) menciona os grupos dos "companheiros de sofrimento", cujos arautos defendem que o grupo verdadeiro, "natural" da pessoa com deficiência, por exemplo, é esse. Portanto, o indivíduo será uma pessoa "leal e autêntica" se se voltar para seu grupo; caso contrário, será "covarde e insensato", segundo o autor. Nesse contexto, identifica-se uma postura de militância, da qual se presume que, quanto mais o grupo se afasta da sociedade a qual desdenha, devido às noções de orgulho, dignidade e independência inerentes a ela, mais eles se tornam parecidos com a mesma. Nesse tipo de alinhamento, a linguagem é política, como mostra Goffman (1988) e concorda Moura (2000). Segundo a autora (2000), o Movimento Surdo centra-se na busca pelo seu "direito como cidadãos, as suas reivindicações sociais e políticas de educação e de trabalho [...]" (MOURA, 2000, p. 13), além de sua inserção na Educação de outros surdos, prevendo-se bem mais de que uma simples "adaptação" ao mundo ouvinte.
Já os alinhamentos exogrupais, para Goffman (1988), exigem que o indivíduo estigmatizado se veja como normal, sendo que os discursos dessas relações têm base psiquiátrica. Goggin e Newell (2003) destacam a presença do discurso médico, que trata a deficiência como incapacidade, em vários setores da sociedade. Nesse contexto, segundo Goffman (1988), cabe ao estigmatizado entender o despreparo dos normais para com o seu traço distintivo, assim como evitar constrangimentos possíveis quanto a ele em situações sociais.

0 exemplo trazido por Goggin e Newell (2003), que menciona "os desafios éticos" do Implante Coclear ${ }^{7}$ ilustra essa situação. Para os defensores da cultura surda, que tem base sociolinguística, a cirurgia, que é recomendada para pessoas com perda profunda ou total de audição, e restaura sua audição, é considerada antiética. Isso porque consistiria no emparelhamento do surdo com um ponto de vista do mundo ouvinte, que tende a seguir 0 discurso médico sobre a deficiência, enfatizando a incapacidade e, com isso, assumindo um aspecto opressivo. Um outro olhar destacado pelos autores (2003) entende o procedimento cirúrgico como uma oportunidade de superação via tecnologia e é identificado com os valores da cultura ouvinte e dominante.

Na busca pela web sobre blogs de deficientes auditivos, foram encontrados seis que trazem 
relatos da experiência de passar a ouvir devido à cirurgia, além de um fórum específico sobre o Implante Coclear. Um deles foi analisado nesta pesquisa. Em outro, uma surda lamenta a posição dominante da cultura surda de ser contra a cirurgia. 0 próximo item traz as questões metodológicas que viabilizaram esse levantamento.

\section{Netnografia aplicada à rede de blogs de deficientes auditivos e de informados}

Para que se entenda de modo mais amplo a aplicação da netnografia neste estudo, vale que se recupere algumas questões referentes à etnografia.

Para Goetz e Lecompte (1988), etnografia é uma reconstrução analítica de cenários e grupos culturais que contempla as crenças, práticas, artefatos e conhecimentos compartilhados pela cultura que está sendo estudada, através de uma imersão profunda do pesquisado no grupo estudado. Segundo Hine (2005), etnografia é uma sistematização em dados da experiência de observações face-a-face, procurando captar uma "performance de comunidade". Goetz e Lecompte (1988) ressaltam que não apenas a re-criação do cenário é importante como resultado de pesquisa, mas também o próprio método utilizado. Quanto a isso, Geertz (1989) destaca que mais do que uma descrição detalhada, a etnografia trata-se de uma interpretação do pesquisador do que seja o ponto de vista do observado, fundando a compreensão dos fenômenos sociais na busca por esse olhar do outro.

A compreensão da web como espaço de observação de comunidades que ali se estabelecem, segundo Hine (2005), pressupõe a constatação de que a internet é simultaneamente contexto cultural e artefato cultural. Na mesma direção, Schneider e Foot (2005) veem a internet como cenário técnico que suporta a ação on-line com implicações sociais, políticas e econômicas.

Neste mesmo sentido, Kozinets (2002) propõe uma adaptação da etnografia para a netnografia, indicando as ressalvas e as oportunidades que devem ser observadas em função de se estar analisando grupos na web, predominantemente à distância.

A palavra Web logs ou blogs ${ }^{8}$, na sua versão abreviada, são ferramentas de fácil atualização em web sites em HTML $^{9}$, que se baseiam no sistema de microconteúdos e na atualização quase que diária dos mesmos. Seu acesso pode ser restrito apenas aos seus criadores, como também, serem compartilhados com um grupo de amigos para permitir as trocas de vivências e opiniões, ou para o público em geral (SHITTINE, 2004).

Jorn Barger utilizou o termo weblog, em 1997, para nomear um conjunto de sites que 
"colecionavam" e divulgavam links interessantes na web, de acordo com Blood (2000). Podese dizer que o surgimento e a evolução das ferramentas de publicaçã $0^{10}$, a partir de 1999, popularizaram os weblogs, proporcionando uma maior facilidade na publicação e manutenção dos sites, que passavam a dispensar conhecimento da linguagem HTML para tanto. Em parte devido a isso, blogs passaram a ser rapidamente adotados e apropriados para os mais diversos usos. A ferramenta de comentários foi agregada mais tarde, e pode-se dizer que ela constitui hoje uma das principais características estruturais dos blogs por possibilitar a interação de leitores de blogs com os seus autores, com o que se configura a socialização on-line neste suporte (AMARAL; MONTARD0; RECUER0, 2009).

Conforme Amaral, Montardo e Recuero (2009), há três formas de se conceituar blogs: estrutural (descreve sua estrutura de publicação, como postagens e comentários), funcional (enfatiza suas funções de comunicação e de socialização) e artefato cultural (visto como um depositário vivo de experiências humanas). Ainda que todas estas conceituações estejam contempladas por este estudo em particular, a dimensão de blog como artefato cultural se destaca aqui.

Neste estudo, a netnografia é utilizada para a seleção da amostra, via buscadores na web, e a obtenção de dados da amostra da rede ${ }^{11}$. Foram encontrados 63 blogs, entre os quais, de pessoas com deficiência auditiva em graus variados, de profissionais (educadores, em sua maioria) ou de ambos. Seis autores de blogs portugueses e cinco de blogs brasileiros concordaram em ter seus blogs observados. Destes, 7 blogs são de autores com deficiência auditiva e 4 de profissionais ou de interessados da/na área.

Além do contato entre os estigmatizados e os "normais"12, existe a situação social mista entre os primeiros e os "informados", segundo Goffman (1988). Os informados são pessoas normais que são aceitas por esses grupos por simpatizar com a sua situação, passando, assim, a desfrutar da intimidade do estigmatizado. Exemplos disso são profissionais, como terapeutas, enfermeiras ou, nesse caso,

Blog, Blogger, Wordpress, Blogdrive, entre outros.

Assim, blogs de deficientes auditivos foram levantados pelo site Pesquisa de Blogs Google e com a ferramenta de busca do site Technorati, a partir de palavras-chave e expressões como "deficiência auditiva", "tenho deficiência auditiva", "sou surdo(a)", etc. Os blogrolls de blogs encontrados também foram investigados quanto à ocorrência de links para blogs de deficientes auditivos. Em seguida, por meio de comentário nos próprios blogs localizados, explicamos o objetivo da pesquisa, deixamos um endereço de e-mail para contato e, também, um link para o blog da pesquisa (Blogs Especiais), que traz o vínculo dos pesquisadores com a Instituição em que se desenvolve o projeto, bem como links para os Currículos Lattes de toda a equipe. Nesse comentário, solicitamos a autorização para observar os blogs levantados, que deveria ser dada por e-mail, endereçado à líder do projeto. Em janeiro de 2007 foi feita a seleção dos blogs e o contato com seus autores. Por essa razão, observou-se as postagens desde janeiro de 2007 até outubro de 2008.

No decorrer do artigo, utilizar-se-á a palavra "normal" tal qual feito por Goffman (1988): pessoa não estigmatizada na relação social considerada, ou seja, a pessoa que não tem deficiência auditiva. 
educadores de surdos. Os pais de pessoas com deficiência também são considerados informados.

Por essa razão, blogs de informados sobre a deficiência auditiva também fazem parte da rede selecionada, sugerindo a possibilidade de análise do estigma em uma rede constituída com base em socialização mista, como mostra 0 item que segue.

\section{Identificação do estigma em blogs de deficientes auditivos}

Desses 11 autores de blogs, seis responderam a um questionário. Entre os temas de interesse, tanto para postagens quanto para leitura em blogs, estão questões relativas à deficiência auditiva aliadas a outros de interesse pessoal. Apenas um respondente colocou a deficiência auditiva como único interesse em blogs. As frases a seguir resumem os objetivos dos respondentes em manterem blogs, os quais, segundo afirmam, foram alcançados:

Promover a problemática da surdez, fazendo-a chegar a um maior número de pessoas, sem ser pelos métodos tradicionais de divulgação...(Respondente informado sobre deficiência auditiva).

Ocupação de tempo livre, expressão de sentimentos pessoais sobre a minha doença, divulgar informações sobre a minha doença e a deficiência auditiva, tentar encontrar 'pares'. (Respondente com deficiência auditiva).

À exceção de um respondente, que tem no blog sua única forma de socialização on-line, todos os demais afirmam utilizar comunicadores instantâneos, redes sociais e todos os meios "que permitam comunicar com o Mundo" (respondente com deficiência auditiva).
Quanto aos temas tratados, os blogs de

deficientes auditivos não se restringem à deficiência auditiva, mas combinam-se a outros temas, ligados ao cotidiano. Conforme já foi posto, o Implante Coclear é uma constante quando o tema é a deficiência auditiva e, consigo, revela outros aspectos da comunidade surda, como mostra os trechos de postagens abaixo:

\begin{abstract}
As minhas conquistas sonoras são tão capazes de esmagar em absoluto os críticos em relação ao Implante Coclear, por isso xô! Escutar é extraordinário! Ainda mais uma benção em discriminar algumas das palavras e melhor do que os sonhos só mesmo a realidade. (Blogueira com deficiência auditiva que fez 0 implante).
\end{abstract}

Ou seja, quer que usemos prótese auditiva quer optemos pelo implante coclear ou que desistamos dessas possibilidades, o respeito pela opção individual é, e deve ser, prevalecido" (Blogueira com deficiência auditiva que usa prótese).

A última citação de blogueira com deficiência auditiva ilustra a posição de Moura (2000) e de Goggin e Newell (2003), quanto à comunidade de surdos não ser homogênea. Além disso, a blogueira, que não usa o Implante Coclear, defende 0 direito de cada surdo em fazer suas próprias escolhas, sem depender das opiniões dos porta-vozes, ou "relações públicas" da cultura surda, como ela os define.

Em um primeiro momento foi curioso destacar que não foi localizada na amostra, em postagens ou em comentários, nenhuma posição contra esse Implante, o que, acredita-se, deve ser uma posição dominante na comunidade de surdos. 
Conforme já foi posto, além dos profissionais interessados em determinada temática, também os pais de pessoas que sofram algum tipo de estigma são considerados informados. Porém, os pais de DA não compõem essa amostra, diferente do que aconteceu em redes estudadas anteriormente.

Encontrar apenas 63 blogs ligados à deficiência auditiva levou a pensar que é bastante limitada a presença desta questão na blogosfera, espaço que favorece a inclusão de várias formas, como mostrado em estudos anteriores. Em um primeiro momento, pensou-se nas limitações em se buscar blogs pelas palavras já informadas (tenho deficiência auditiva, sou surdo(a), etc.). A seguir, veio à tona a questão da visibilidade de um estigma, apontada por Goffman (1988). Sobre a visibilidade, 0 autor afirma que "o que pode ser dito sobre a identidade social de um indivíduo em sua rotina diária e por todas as pessoas que ele encontra nela será de grande importância para ele" (GOFFMAN, 1988; p.58), influenciando nas situações sociais. Porém, a pessoa pode simplesmente optar por não se identificar na web por meio de um atributo que possa ser objeto de estigma, o que, em outras situações sociais, poderia ser impossível. Isso reduz a amostra encontrada pelos métodos aqui selecionados e ilustra a ocorrência do encobertamento, questão ligada, de certa forma, à questão da visibilidade. Nas palavras do autor:

Sabe-se que as pessoas que estão prontas a admitir que têm um estigma podem, não obstante, fazer grandes esforços para que ele não apareça muito. 0 objetivo do indivíduo é reduzir a tensão, ou seja, tornar mais fácil para si mesmo e para os outros uma redução dissimulada ao estigma, $\mathrm{e}$ manter um envolvimento espontâneo no conteúdo público da interação. (GOFFMAN, 1988, p. 113).

Quanto questionados sobre as vantagens de se ter um blog, duas respostas fazem referência à questão dos alinhamentos intra e exogrupais e exemplificam uma preocupação geral na amostra:

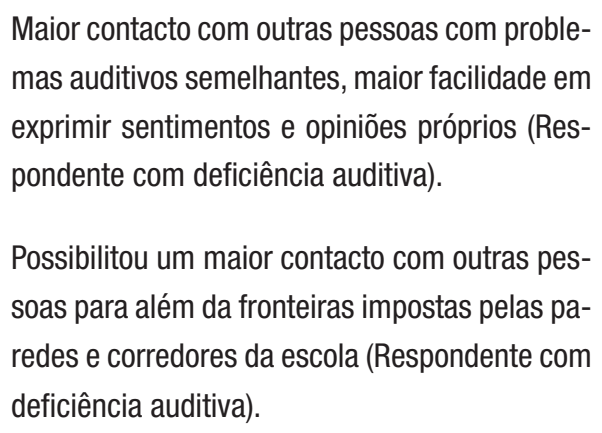
mas auditivos semelhantes, maior facilidade em exprimir sentimentos e opiniões próprios (Respondente com deficiência auditiva).

Possibilitou um maior contacto com outras pessoas para além da fronteiras impostas pelas paredes e corredores da escola (Respondente com deficiência auditiva).

Acredita-se, então, que os deficientes auditivos estão buscando mais contato com outros deficientes auditivos, mas não deixam de lado a sociedade em geral, tentando não apenas apresentar para a mesma esta deficiência, mas também interagir com ela independente disso.

Organizou-se tabelas com o conteúdo das 230 postagens e 243 comentários para viabilizar a análise pretendida quanto à identificação do estigma nessa rede. Em apenas dois blogs verificou-se essa ocorrência (4 postagens e 3 comentários), cujo teor refletia as questões enfrentadas no dia a dia dos blogueiros quanto ao estigma.

No primeiro blog, o estigma aparece em apenas uma de todas as postagens do autor do site, onde ele diz: 
Portanto, meu "defeituoso" amigo, tenha um bom dia e lembre de regar as flores do seu lado do caminho... e envie este e-mail a algum (ou a todos) os seus "defeituosos" amigos. Sem esquecer que é "defeituoso" também quem a mandou a você! (Blogueiro com deficiência auditiva)

0 estigma aparece na palavra "defeituoso", citada entre aspas. De alguma forma, ele está externando para leitores, deficientes ou não, a sua deficiência, mesmo que de alguma forma essa postagem possa ser uma brincadeira. Mas como ele se dirige apenas aos "defeituosos" amigos, ou seja, aos surdos como ele, nota-se a presença do alinhamento intragrupal (GOFFMAN, 1988).

Em um outro blog, o estigma foi encontrado em três postagens. Na primeira, ele aparece no momento em que a autora escreve que:

A meu ver, a sociedade está cada vez mais receptiva em lidar com os cidadãos portadores de deficiência, ao nível social. Há ouvintes que se interessam por se integrar na comunidade surda, aprendendo a língua dela. Outros se esforçam por se fazerem entender pelos surdos. (Blogueira com deficiência auditiva)

E no comentário da mesma:

[...] fico muito contente por sentires que há menos discriminação relativemnte [sic!] aos surdos. Nem que sejam pequenas mudanças, é importante que se vá avançando e não recuando (Comentarista ouvinte).

Nota-se aqui a referência ao alinhamento exogrupal entre deficiente auditiva e ouvinte.

Já no comentário, percebe-se a presença do estigma pois esta amiga concorda com a ideia da postagem, e fica contente de a "amiga" sentir que há menos discriminação em relação aos surdos, configurando alinhamento exogrupal. $\mathrm{Na}$ segunda postagem em que o estigma aparece neste mesmo blog, a autora fala da heterogeneidade da comunidade dos surdos:

Quando se fala em "comunidade", a priori afirmamos tratar-se de um grupo de pessoas com um conjunto de características, opiniões, juízos de valor, cultura, conhecimentos e estatuto social semelhantes. A comunidade surda, existe, tal como outras comunidades e agrupamentos sociais. Interessa salientar que, pelo que sei, nem todos os surdos pertencem à dita comunidade.

[...]a sociedade ouvinte, julga erroneamente que todos os surdos são como esses, falam através da LGP, têm modos de pensar e/ou agir similares, têm o mesmo nível cultural, têm as mesmas escolhas ao nível das ajudas técnicas [...].

[...]atrevo-me dizer, que provavelmente, existem mais surdos que não pertencem às "ditas comunidades", por motivos alheios. (Blogueira com deficiência auditiva, grifo nosso)

Comentário a essa postagem refere à mesma questão:

Pergunto-te 0 seguinte: surdos oralistas, qdo estão juntos, sem ouvintes por perto, não comunicam por gestos? Pergunto-te ainda outra coisa: surdos como tu e tuas amigas interagem normalmente com ouvintes no dia a dia e não sentem necessidade de se reunirem só entre surdos? Quando falas em sub-comunidades, referes-te a comunidades surdas oralistas, ou esses não "precisam" de uma comunidade especifica e vivem completamente integrados na comunidade ouvinte? Termino dizendo que acho que tens toda a razão: tal como na sociedade em geral, a pluralidade e a heterogeneidade devem se respeitadas! Um grande beijinho (Comentarista ouvinte). 
Nesta postagem e no comentário respectivo, observa-se 0 alinhamento exogrupal (GOFFMAN, 1988). A blogueira em questão externa sua opinião, afirmando que respeita tanto aqueles que se limitam a uma comunidade de surdos, quanto aqueles que não se limitam, defendendo a livre escolha de cada um. Expressa sua opinião de uma forma exclamativa, principalmente visando pessoas que não respeitam uma dessas visões, nomeadamente representantes da comunidade surda. Já no comentário, uma ouvinte revela toda a sua curiosidade por esta questão.

Na terceira e última postagem, o estigma aparece quando a blogueira afirma que:

[...]é sempre um privilégio elucidar-te sobre a minha e a situação de muitos surdos, apelidados de 'oralistas'.

[...]Digo que não é fácil de nos reunirmos dado que muitos estão interligados com a sociedade, tal como eu, a não ser que estes se façam ouvir através da Internet (Blogueira com deficiência auditiva).

Aqui é interessante perceber que a internet aparece como ambiente favorável aos apelidados "surdos oralistas", que conhecem a língua portuguesa e que podem acessar ferramentas de socialização pela web. Esta blogueira, apesar de não ter recorrido ao Implante Coclear, usa prótese, por isso é identificada como oralista. Um comentário em agradecimento à blogueira feito pela mesma leitora ouvinte encerra a conversa:

Agradeço-te, mais uma vez, a paciência que tens para me esclarecer as dúvidas (Comentarista ouvinte).

\section{Considerações finais}

Feita a identificação de estigma em blogs de deficientes auditivos, percebe-se, em primeiro lugar, a sua baixa ocorrência (4 postagens de 230 e 3 comentários de 243). Além da hipótese de que a socialização observada na rede sobre deficiência auditiva em blogs possa ser um reflexo de uma sociedade que revela um amadurecimento quanto às diferenças seja responsável por essa baixa ocorrência, indícios encontrados neste estudo revelam também uma outra possibilidade.

É em referências a conflitos provenientes de alinhamentos intragrupais dos deficientes auditivos que se localizam a maior parte das incidências de estigma nas postagens e comentários. Segundo Goffman (1988), para o estigmatizado, a associação ou distanciamento com relação aos seus iguais pode provocar oscilações de identidade, numa alternância entre a decisão de se assumir como surdo ou na adoção dos valores da cultura ouvinte.

Como indícios dessa situação, lista-se questões trazidas na bibliografia especializada sobre deficiência auditiva e sobre o uso de tecnologias por parte de pessoas com deficiência, além da leitura detalhada dos blogs da amostra, em postagens e em comentários. Fala-se em indícios porque se entende como parte da estratégia de preservação de valores caros a uma parcela da comunidade dos surdos o uso de linguagem de sinais como forma única de comunicação, na busca pela identidade surda 
definida em sua positividade. Deduz-se que essa decisão dificulte, se não impossibilite, o uso de ferramentas de socialização on-line, baseadas na língua portuguesa, relacionada com os valores da cultura ouvinte.

Portanto, a web não é o espaço privilegiado de embate entre essas correntes a respeito da cultura surda, sendo que se localizou apenas um dos lados da questão presente nesse ambiente, lado esse favorável a implantes, ao uso de tecnologias corretivas da audição, ou de acordo com a cultura ouvinte, por assim dizer. No entanto, a partir somente da presença do ponto de vista desse lado, foi possível identificar a ocorrência de estigma entre os próprios deficientes auditivos.

\section{Referências}

AMARAL, Adriana; MONTARD0, Sandra Portella; RECUERO, Raquel. Blogs.com: estudos sobre blogs e comunicação. São Paulo: Momento Editorial, 2009. Disponível em: <http://www.sobreblogs.com.br>. Acesso em: 05 abr. 2009.

AZEVEDO, Paulo Henrique; BARROS, Jônatas de França. 0 nível de participação do Estado na gestão do esporte brasileiro como fator de inclusão social de pessoas portadoras de deficiência. Revista Brasileira de Ci e Movimento, Brasília, v. 12, n. 1, p. 77-84, jan. mar. 2004.

BL00D, Rebecca. Weblogs: a history and perspective. 2000. Disponível em: <http://www. rebeccablood.net/essays/weblog_history.html>. Acesso em: 30 jul. 2008.

GEERTZ, Clifford. A interpretação das culturas. Rio de Janeiro: Guanabara, 1989.
G0ETZ, Judith Preissle; LECOMPTE, Margaret. Etnografia y diseño cualitativo en investigación educativa. Madri: Morata, 1988.

GOFFMAN, Erving. Estigma: notas sobre a manipulação da identidade deteriorada. 4 ed. Rio de Janeiro: Guanabara, 1988.

GOGGIN, Gerard; NEWELL, Christopher. Digital disability: the social construction of disability in new media. Maryland: Rowman \& Littlefield, 2003.

HINE, Christine (ed.). Virtual methods: issues in social research on the internet. 0xford: Berg, 2005.

KOZINETS, Robert. The field behind the screen. Using Netnography for marketing research in online communities, 2002. Disponível em: < http://www. marketingpower.com/content18255.php>. Acesso em: 9 abr. 2009.

LADEIRA, Fernanda; AMARAL, Isabel. A educação de alunos com multideficiência nas Escolas de Ensino Regular. Lisboa: Ministério da Educação; Departamento da Educação Básica, 1999. (Coleção Apoios Educativos)

MONTARD0, Sandra Portella. Redes temáticas na web e biossocialidade on-line. In: ENCONTRO DA ASSOCIAÇÃO NACIONAL DE PROGRAMAS DE PÓSGRADUAÇÃO DE COMUNICAÇÃO, 18., Belo Horizonte, 2009. Anais... Belo Horizonte: Compós, 2009.

Fotos que fazem falar: desafios metodológicos para análise de redes temáticas em fotologs. Revista Famecos, Porto Alegre, n. 37, p. 75-84, dez. 2008. Disponível em: <http://www.pucrs.br/famecos/pos>. Acesso em: 2 abr. 2009. ; GOEDTEL, Elias Ferreira; ETCHEGARAY, Maite Scherer. Redes temáticas em fotologs: proposições iniciais para 0 estudo de caso sobre Síndrome de Down (SD). Revista Novas Tecnologias na Educação (Renote), Porto Alegre, v. 6, n. 1, jul. 2008. Disponível em: <http://www.cinted.ufrgs.br/renote/ jul2008/artigos/4a_sandra.pdf> Acesso em: 2 abr. 2009. 
; PASSERINO, Liliana. Espelhos quebrados no ciberespaço: implicações de redes temáticas em blogs na Análise de Redes Sociais (ARS). In: ENCONTRO DA ASSOCIAÇÃO NACIONAL DE PROGRAMAS DE PÓS-GRADUAÇÃO DE COMUNICAÇÃO, 17., São Paulo, 2008. Anais... São Paulo: Compós, 2008. Disponível em: $<$ http://www.compos.org.br>. Acesso em: 10 abr. 2009. Inclusão social via acessibilidade digital: proposta de inclusão digital para Pessoas com Necessidades Especiais(PNE). eCompós, Brasília, v. 8, abr.2007. Disponível em:<http://www.compos.org. br/ecompos/adm/documentos/ecompos08_abril2007_ passerino_montardo.pdf >. Acesso em: 10 abr. 2009. Estudo dos blogs a partir da netnografia: possibilidades e limitações. Renote. Porto Alegre: UFRGS, Vol. 4, no. 2, Dez. 2006. Disponível em: <http://www.cinted.ufrgs.br/renote/dez2006/ artigosrenote/25065.pdf>. Acesso em 10 abr. 2009. MOURA, Maria Cecília. o Surdo: caminhos para uma nova identidade. São Paulo: Revinter, 2000.

REDONDO, Maria Cristina; CARVALHO, Josefina Martins. Deficiência auditiva. Deficiência auditiva. Brasília: MEC/Secretaria de Educação a Distância, 2000. (Cadernos da TV Escola)

SCHNEIDER, Steven. FOOT, Kirsten. Web sphere analysis: an approach to studying online action. In: HINE, Christine (org.).Virtual methods. Issues in social research on the Internet. Oxford: Berg, 2005.

SHITTINE, Denise. Blog: comunicação e escrita íntima na internet. Rio de Janeiro: Civilização Brasileira, 2004. SPOSATI, Aldaíza .A fluidez da inclusão/exclusão social. Ciência e Cultura, São Paulo, vol. 58, n. 4, out. - dez. 2006.

WARSCHAUER, Mark. Tecnologia e inclusão social. A exclusão digital em debate. São Paulo: Senac, 2006. 


\section{Stigma in hearing-impaired people's blogs}

\section{Estigma en blogs de personas con deficiencia auditiva}

\section{Abstract}

This work aims to identify stigma in hearingimpaired people's blogs. The fact that there are hearing-impaired people as authors of blogs justifies the reasearch on the concept of stigma (GOFFMAN, 1988) and the checking of its incidence on such network. Concerning methodology, netnography is used for identifying, selecting and obtaining data from the selected blogs. This study has observed low occurrence of stigma in posts and in comments.

\section{Keywords}

Stigma. Blogs. Hearing-impaired people.

\section{Resumen}

El tema de este trabajo es la identificación del estigma en blogs de personas con deficiencia auditiva. En esta red, los deficientes auditivos son autores de blogs, lo que justifica la investigación del concepto de estigma (GOFFMAN,1988 y la verificación de su incidencia en la red considerada. Con relación a la metodologia, la netnografia (HINE, 2005; KOZINETS, 2002) ha sido utilizada para la identificación, selección y obtención de datos de los blogs escogidos. Fue posible verificar una baja ocurrencia del estigma en posts y comentarios. Sin embargo, en la mayoría de estas ocurrencias el contexto de su surgimiento era consecuencia de cuestiones relacionadas al alineamiento intragrupal de deficientes auditivos.

\section{Palabras clave}

Estigma. Blogs. Personas con deficiencia auditiva. 


\section{Expediente}

A revista E-Compós é a publicação científica em formato eletrônico da Associação Nacional dos Programas de Pós-Graduação em Comunicação (Compós). Lançada em 2004, tem como principal finalidade difundir a produção acadêmica de pesquisadores da área de Comunicação, inseridos em instituições do Brasil e do exterior.
E-COMPÓS I www.e-compos.org.br I E-ISSN 1808-2599

Revista da Associação Nacional dos Programas de Pós-Graduação em Comunicação. Brasília, v.12, n.1, jan./abr. 2009.

A identificação das edições, a partir de 2008 passa a ser volume anual com três números.

\section{CONSELHO EDITORIAL}

\section{Afonso Albuquerque}

Universidade Federal Fluminense, Brasil

Alberto Carlos Augusto Klein

Universidade Estadual de Londrina, Brasi

Alex Fernando Teixeira Primo

Universidade Federal do Rio Grande do Sul, Brasil

\section{Alfredo Vizeu}

Universidade Federal de Pernambuco, Brasil

Ana Carolina Damboriarena Escosteguy

Pontifícia Universidade Católica do Rio Grande do Sul, Bras

Ana Silvia Lopes Davi Médola

Universidade Estadual Paulista, Brasil

André Luiz Martins Lemos

Universidade Federal da Bahia, Brasil

Ângela Freire Prysthon

Universidade Federal de Pernambuco, Brasil

Antônio Fausto Neto

Universidade do Vale do Rio dos Sinos, Brasil

Antonio Carlos Hohlfeldt

Pontifícia Universidade Católica do Rio Grande do Sul, Brasil

Arlindo Ribeiro Machado

Universidade de São Paulo, Brasil

César Geraldo Guimarães

Universidade Federal de Minas Gerais, Brasil

Cristiane Freitas Gutfreind

Pontifícia Universidade Católica do Rio Grande do Sul, Brasil

Denilson Lopes

Universidade Federal do Rio de Janeiro, Brasil

Eduardo Peñuela Cañizal

Universidade Paulista, Brasi

Erick Felinto de Oliveira

Universidade do Estado do Rio de Janeiro, Brasil

Francisco Menezes Martins

Universidade Tuiuti do Paraná, Brasil

Gelson Santana

Universidade Anhembi/Morumbi, Brasi

Hector Ospina

Universidad de Manizales, Colômbia

leda Tucherman

Universidade Federal do Rio de Janeiro, Brasil

Itania Maria Mota Gomes

Universidade Federal da Bahia, Brasil

Janice Caiafa

Universidade Federal do Rio de Janeiro, Brasil

Jeder Silveira Janotti Junior

Universidade Federal da Bahia, Brasil

\section{João Freire Filho}

Universidade Federal do Rio de Janeiro, Brasil

John DH Downing

University of Texas at Austin, Estados Unidos

José Luiz Aidar Prado

Pontifícia Universidade Católica de São Paulo, Brasil

José Luiz Warren Jardim Gomes Braga

Universidade do Vale do Rio dos Sinos, Brasil

Juremir Machado da Silva

Pontifícia Universidade Católica do Rio Grande do Sul, Brasil

Lorraine Leu

University of Bristol, Grã-Bretanha

Luiz Claudio Martino

Universidade de Brasília, Brasil

Maria Immacolata Vassallo de Lopes

Universidade de São Paulo, Brasil

Maria Lucia Santaella

Pontifícia Universidade Católica de São Paulo, Brasil

Mauro Pereira Porto

Tulane University, Estados Unidos

Muniz Sodre de Araujo Cabral

Universidade Federal do Rio de Janeiro, Brasil

Nilda Aparecida Jacks

Universidade Federal do Rio Grande do Sul, Brasil

Paulo Roberto Gibaldi Vaz

Universidade Federal do Rio de Janeiro, Brasil

Renato Cordeiro Gomes

Pontifícia Universidade Católica do Rio de Janeiro, Brasil

Ronaldo George Hela

Universidade do Estado do Rio de Janeiro, Brasil

Rosana de Lima Soares

Universidade de São Paulo, Brasil

Rossana Reguillo

Instituto Tecnológico y de Estudios Superiores do Occidente, México

Rousiley Celi Moreira Maia

Universidade Federal de Minas Gerais, Brasil

Sebastião Carlos de Morais Squirra

Universidade Metodista de São Paulo, Brasi

Simone Maria Andrade Pereira de Sá

Universidade Federal Fluminense, Brasil

Suzete Venturelli

Universidade de Brasília, Brasil

Valério Cruz Brittos

Universidade do Vale do Rio dos Sinos, Brasil

Veneza Mayora Ronsini

Universidade Federal de Santa Maria, Brasil

Vera Regina Veiga França

Universidade Federal de Minas Gerais, Brasil
COMISSÃO EDITORIAL

Ana Gruszynski I Universidade Federal do Rio Grande do Sul, Brasil

Rose Melo Rocha I Escola Superior de Propaganda e Marketing, Brasil

CONSULTORES AD HOC

Alberto Schneider I Visitante Tokyo University

Alexandre Rocha da Silva I Universidade Federal do Rio Grande do Sul, Brasil

Fernanda Bruno I Universidade Federal do Rio de Janeiro, Brasil

Ida Stumpf I Universidade Federal do Rio Grande do Sul, Brasil

Kati Caetano I Universidade Tuiuti do Paraná, Brasil

Laura Cánepa I Universidade Anhembi Morumbi, Brasi

Malena Contrera I Universidade Paulista, Brasil

Sandra Gonçalves I Universidade Federal do Rio Grande do Sul, Brasil

Vicente Gosciola I Universidade Anhembi Morumbi, Brasil

REVISÃO DE TEXTO E TRADUÇÃo I Everton Cardoso

EDITORAÇ̃̃o ELETRÔNICA I Raquel Castedo
COMPós I www.compos.org.br

Associação Nacional dos Programas de Pós-Graduação em Comunicação

Presidente

Erick Felinto de Oliveira

Universidade do Estado do Rio de Janeiro, Brasil erickfelinto@uol.com.br

Vice-presidente

Ana Silvia Lopes Davi Médola

Universidade Estadual Paulista, Brasil

asilvia@faac.unesp.br

Secretária-Geral

Denize Correa Araújo

Universidade Tuiuti do Paraná, Brasil

denizearaujo@hotmail.com 